\title{
Functionally Rigid and Degenerate Molecular Shuttles
}

\author{
Il Yoon, ${ }^{[b]}$ Diego Benítez, ${ }^{[b]}$ Yan-Li Zhao, ${ }^{[b]}$ Ognjen Š. Miljanić, ${ }^{[b]}$ Soo-Young Kim, ${ }^{[b]}$ \\ Ekaterina Tkatchouk, ${ }^{[c]}$ Ken C.-F. Leung, ${ }^{[b]}$ Saeed I. Khan, ${ }^{[b]}$ \\ William A. Goddard, III, ${ }^{[\mathrm{c}]}$ and J. Fraser Stoddart*[a, b]
}

\begin{abstract}
The preparation and dynamic behavior of two functionally rigid and degenerate [2] rotaxanes $\left(\mathbf{1} \cdot 4 \mathrm{PF}_{6}\right.$ and $\left.\mathbf{2} \cdot 4 \mathrm{PF}_{6}\right)$ in which a $\pi$-electron deficient tetracationic cyclophane, cyclobis(paraquat- $p$-phenylene) $\left(\mathrm{CBPQT}^{4+}\right)$ ring, shuttles back and forth between two $\pi$ electron-rich naphthalene (NP) stations by making the passage along an ethynyl-phenylene-(PH)-ethynyl or butadiyne rod, are described. The [2]rotaxanes were synthesized by using the clipping approach to template-directed synthesis, and were characterized by NMR spectroscopic and mass spectrometric analyses. ${ }^{1} \mathrm{H}$ NMR spectra of both [2] rotaxanes show evidence for the formation of mechanically interlocked structures, resulting in the upfield shifts of the resonances for key protons on the dumbbell-shaped components. In particular, the signals for the peri protons on the NP units in the
\end{abstract}

dumbbell-shaped components experienced significant upfield shifts at low temperatures, just as has been observed in the flexible [2]rotaxanes. Interestingly, the resonances for the same protons did not exhibit a significant upfield shift at $298 \mathrm{~K}$, but rather only a modest shift. This phenomenon arises from the much reduced binding of the ethynyl$\mathrm{NP}$ unit compared to the 1,5-dioxy-NP unit. This effect, in turn, increases the shuttling rate when compared to the 1,5-dioxy-NP-based rotaxane systems investigated previously. The kinetic and thermodynamic data of the shuttling behavior of the $\mathrm{CBPQT}^{4+}$ ring between the NP units were obtained by

Keywords: molecular modeling molecular shuttles $\cdot$ rotaxanes self-assembly • template-directed synthesis variable-temperature NMR spectroscopy and using the coalescence method to calculate the free energies of activation $\left(\Delta G_{\mathrm{c}}{ }^{\neq}\right)$of 9.6 and $10.3 \mathrm{kcal} \mathrm{mol}^{-1}$ for $\mathbf{1 . 4} \mathrm{PF}_{6}$ and $\mathbf{2} \cdot 4 \mathrm{PF}_{6}$, respectively, probed by using the rotaxane's $\alpha$-bipyridinium protons. The solid-state structure of the free dumbbell-shaped compound (3) shows the fully rigid ethynylPH-ethynyl linker with a length $(8.1 \AA)$ twice as long as that $(3.8 \AA)$ of the butadiyne linker. Full-atomistic simulations were carried out with the DREIDING force field (FF) to probe the degenerate molecular shuttling processes, and afforded shuttling energy barriers $\left(\Delta G^{\neq}=10.4 \mathrm{kcal} \mathrm{mol}^{-1}\right.$ for $1.4 \mathrm{PF}_{6}$ and $2.4 \mathrm{PF}_{6}$ ) that are in good agreement with the experimental values $\left(\Delta G_{\mathrm{c}}{ }^{*}=9.6\right.$ and $10.3 \mathrm{kcal} \mathrm{mol}^{-1}$ for $\mathbf{1} \cdot 4 \mathrm{PF}_{6}$ and $\mathbf{2} \cdot 4 \mathrm{PF}_{6}$, respectively, probed by using their $\alpha$-bipyridinium protons).

\section{Introduction}

[a] Prof. Dr. J. F. Stoddart

Department of Chemistry, Northwestern University

2145 Sheridan Road, Evanston, IL 60208 (USA)

Fax: (+1) 847-491-7713

[b] Dr. I. Yoon, Dr. D. Benítez, Dr. Y.-L. Zhao, Dr. O. Š. Miljanić, Dr. S.-Y. Kim, Dr. K. C.-F. Leung, Dr. S. I. Khan,

Prof. Dr. J. F. Stoddart

Department of Chemistry and Biochemistry

University of California, Los Angeles

405 Hilgard Avenue, Los Angeles, CA 90095 (USA)

[c] Dr. E. Tkatchouk, Prof. Dr. W. A. Goddard, III

Materials and Process Simulation Center

California Institute of Technology

Pasadena, CA 91125 (USA)

Supporting information for this article is available on the WWW under http://dx.doi.org/10.1002/chem.200802096.
Bistable [2]rotaxanes, ${ }^{[1]}$ which have evolved over the past couple of decades from degenerate molecular shuttles, ${ }^{[2]}$ are playing an emergent role in the development of molecular nanotechnology ${ }^{[3]}$ To date, they have already shown important applications in the fabrication of molecular electronic devices (MEDs) ${ }^{[4]}$ and in the construction of nanoelectromechanical systems (NEMS). ${ }^{[3,4]} \pi$-Electron rich 1,5-disubstituted naphthalene (NP) ring systems encircled by the $\pi$-electron-deficient tetracationic cyclophane, cyclobis(paraquat- $p$ phenylene) $\left(\mathrm{CBPQT}^{4+}\right)$, constitute a well-known ${ }^{[5]}$ donoracceptor recognition motif. Introduction of rigidity through the incorporation of NP, monopyrrolotetrathiafulvalene $(\mathrm{MPTTF}),{ }^{[1 \mathrm{a}, 6]}$ and bispyrrolotetrathiafulvalene $(\mathrm{BPTTF})^{[7]}$ 
into the dumbbell-shaped components of bistable [2]rotaxanes and their degenerate molecular shuttle progenitors limits the number of geometries that can be adopted in condensed media, as well as in the solution and crystalline phases. This increased constitutional rigidity in the dumbbell backbone of [2] rotaxanes is advantageous in the design of switches and machines since it limits the different number of geometries that a rotaxane can adopt in condensed media which often constitutes device settings. ${ }^{[3,4]}$ Furthermore, the structural rigidity is also favorable for the fabrication of surface-based machinery ${ }^{[8]}$ because of the absence of back-folding $^{[9]}$ by the free recognition site. Recently, we reported ${ }^{[10]}$ the preparation of two [2]rotaxanes with rigid spacers between their two recognition sites either two NPs or an MPTTF and an NP in which the rigid system simplifies both the structures and functions with respect to related bistable [2] rotaxanes $^{[1]}$ with flexible spacers.

The degenerate NP/NP [2] rotaxane $\left(\mathbf{2} \cdot 4 \mathrm{PF}_{6}\right.$ in Figure 1) was synthesized $^{[10]}$ to probe the shuttling barrier (by dynamic ${ }^{1}$ H NMR spectroscopy) for the movement of the
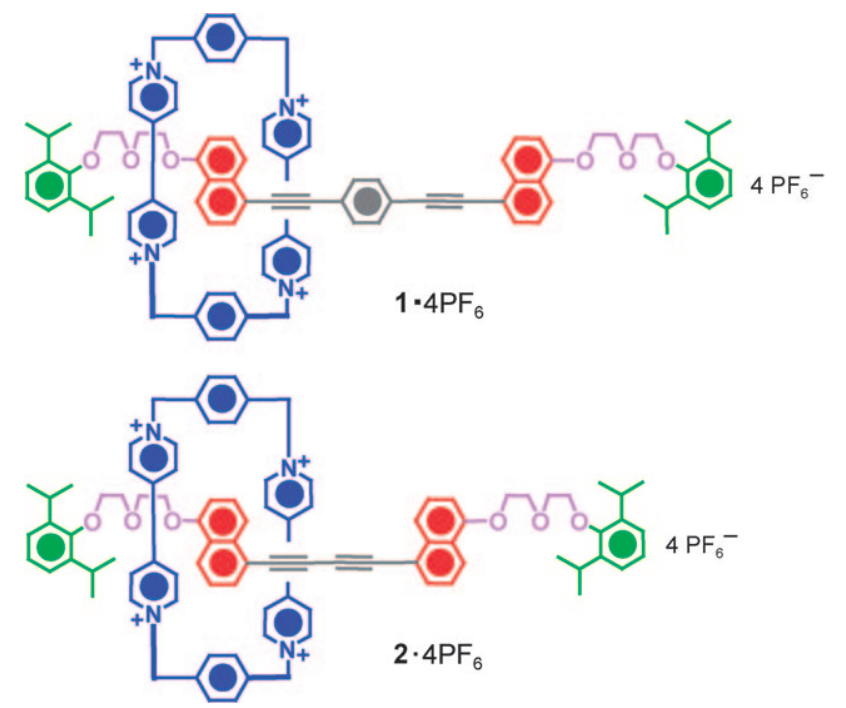

Figure 1. Structural formulas of the degenerate [2] rotaxanes $\mathbf{1 . 4} \mathrm{PF}_{6}$ and 2.4 $\mathrm{PF}_{6}$.

$\mathrm{CBPQT}^{4+}$ ring along the rigid butadiyne spacer. The solidstate structures of the [2] rotaxane $\mathbf{2} \cdot 4 \mathrm{PF}_{6}$ and its free dumbbell compound have been reported previously. ${ }^{[11]}$ From the solid-state structure, the length of the rigid butadiyne linker was found to be $3.8 \AA \AA^{[11]}$ To investigate the shuttling behavior of the [2] rotaxane with an extended rigid linker between two NP units on its dumbbell backbone, a phenylene (PH) unit between two ethynyl units on the dumbbell backbone has now been introduced into the system, resulting (Figure 1 and Scheme 1) in the [2]rotaxane $1.4 \mathrm{PF}_{6}$ and its dumbbellshaped compound $\mathbf{3}$.

Here, we describe the template-directed ${ }^{[12]}$ synthesis (Scheme 1 and 2) of a rigid and degenerate molecular shuttle, namely the donor-acceptor [2] rotaxane $\mathbf{1} \cdot 4 \mathrm{PF}_{6}$ contain- ing the longer ethynyl-PH-ethynyl linker, by a clipping reaction under high-pressure ${ }^{[13]}$ through the macrocyclization of the subunits of the macrocyclic component around the NP station of the dumbbell-shaped component in $1.4 \mathrm{PF}_{6}$ (Scheme 2), which was characterized by ${ }^{1} \mathrm{H}$ NMR spectroscopic and electrospray ionization mass spectrometric (ESIMS) analyses. Moreover, we have employed variable-temperature (VT) ${ }^{1} \mathrm{H}$ NMR spectroscopy to calculate the switching rates of the molecular shuttles. The solid-state superstructure of the dumbbell-shaped compound $\mathbf{3}$ has also been obtained. Finally, probing of the degenerate shuttling process using molecular dynamic (MD) simulations in both molecular shuttles $\mathbf{1} \cdot 4 \mathrm{PF}_{6}$ and $2 \cdot 4 \mathrm{PF}_{6}$ was carried out by using the DREIDING force field, ${ }^{[14]}$ which was described ${ }^{[11]}$ recently along with the experimental and calculated solidstate structure of $2 \cdot 4 \mathrm{PF}_{6}$.

\section{Results and Discussion}

Synthesis: The route for the synthesis of the [2]rotaxane $1 \cdot 4 \mathrm{PF}_{6}$ containing the ethynyl-PH-ethynyl linker between the two NP units is shown in Scheme 1 and 2. The dumbbell-shaped compound 3 was prepared in $50 \%$ yield by combining a 2:1 ratio of compound $\mathbf{5}$, a monotosylated diethyleneglycol carrying a 2,6-diisopropylphenyl ether at its other end, with compound 7, the fully rigid backbone of the dumbbell component, in the presence of $\mathrm{K}_{2} \mathrm{CO}_{3}$ in $\mathrm{MeCN}$. Tosylation of the compound $\mathbf{4}$, which was obtained following a literature ${ }^{[10]}$ procedure, afforded compound $\mathbf{5}$ in $87 \%$ yield. Compound 7 was obtained by using the Sonogashira ${ }^{[15]}$ coupling reaction between 5-iodonaphthol ${ }^{[10]}$ and 1,4-diethynylbenzene in $75 \%$ yield (Scheme 1 ). The degenerate molecular shuttle $1.4 \mathrm{PF}_{6}$, was synthesized from the dumbbellshaped compound $\mathbf{3}$ and the precursors $\mathbf{8} \cdot 2 \mathrm{PF}_{6}{ }^{[16]}$ and $p$-di-

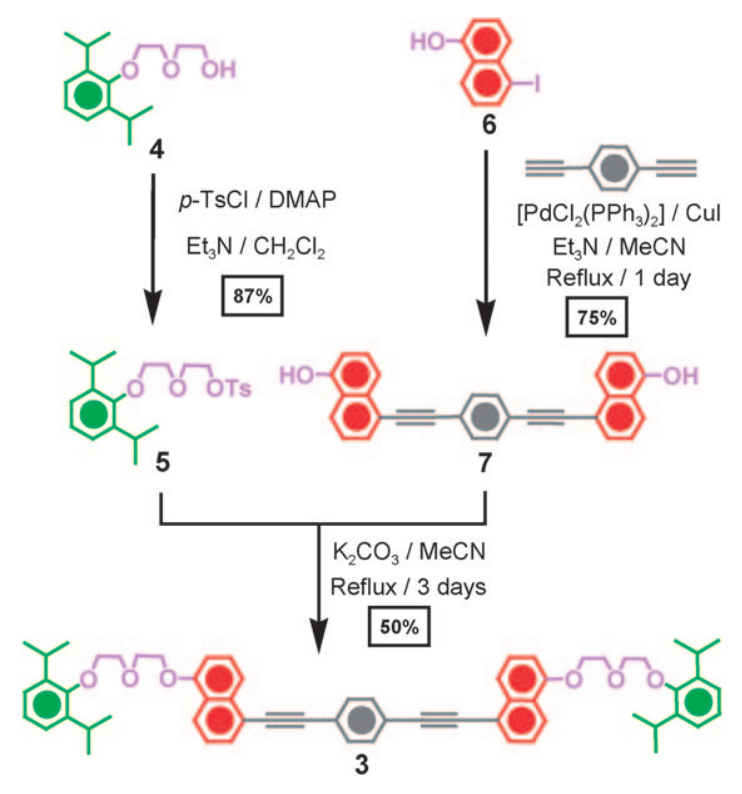

Scheme 1. Synthesis of the dumbbell compound $\mathbf{3}$ containing NP units. 
bromoxylene in DMF using a template-directed clipping approach under high pressure (Scheme 2). The [2]rotaxane $1.4 \mathrm{PF}_{6}$ was isolated as a red solid in $10 \%$ yield after column chromatography on silica gel using $\mathrm{Me}_{2} \mathrm{CO} / \mathrm{NH}_{4} \mathrm{PF}_{6}$ (100:1 $\mathrm{v} / \mathrm{w})$ as the eluent followed by column chromatography on alumina using $\mathrm{MeOH} / 2 \mathrm{M} \mathrm{NH}_{4} \mathrm{Cl}(9.5: 0.5 \mathrm{v} / \mathrm{w})$ as the eluent.

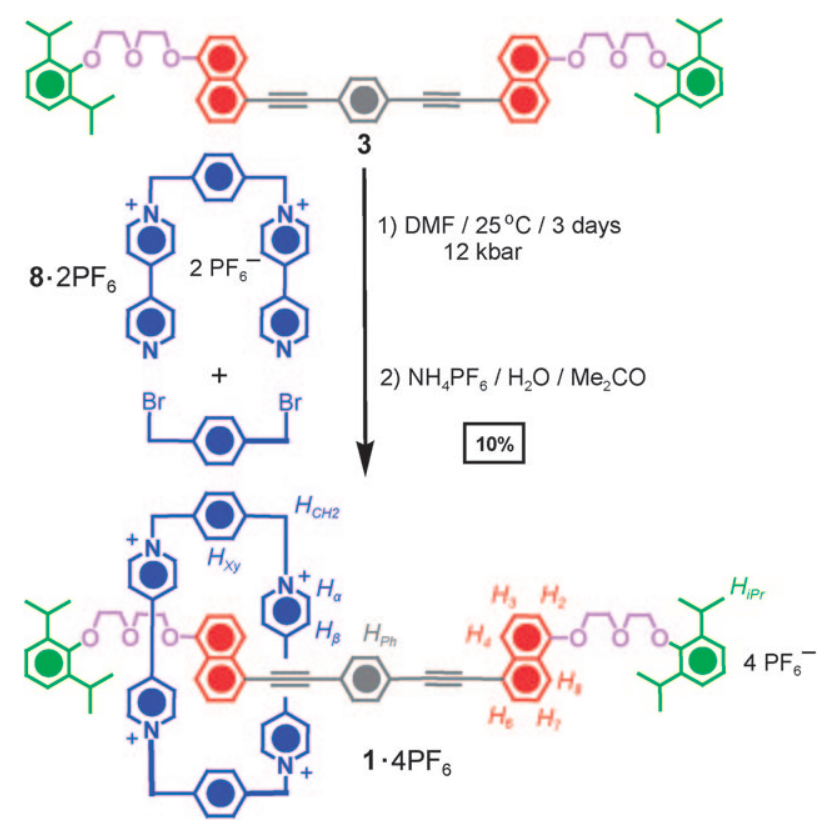

Scheme 2. Synthesis of the degenerate [2] rotaxane $\mathbf{1 . 4} \mathrm{PF}_{6}$.

The synthesis of $\mathbf{2} \cdot 4 \mathrm{PF}_{6}$ was carried out previously ${ }^{[10,11]}$ by two different methods. The first low-yielding $(8 \%)^{[10]}$ synthesis of $2 \cdot 4 \mathrm{PF}_{6}$ using a template-directed clipping approach under high pressure reaction called for the development of a higher yielding synthesis. Our subsequent success ${ }^{[17]}$ in making catenanes by employing $\mathrm{Cu}^{2+}$-mediated Eglinton ${ }^{[18]}$ coupling as the final step encouraged us to improve $(18 \%$ yield) the preparation of $2 \cdot 4 \mathrm{PF}_{6}$ in which the crucial mechanical bond-forming step relies on the Eglinton dimerization of the two half dumbbell molecules with terminal alkyne functions. ${ }^{[11]}$
Mass spectrometric investigation: The [2] rotaxane $\mathbf{1} \cdot 4 \mathrm{PF}_{6}$ was characterized by electrospray ionization mass spectrometry (ESI-MS) which revealed (see Figure S1 and S2 in the Supporting Information) peaks at $m / z$ 1863, 859, and 524, corresponding to the loss of one, two, and three $\mathrm{PF}_{6}{ }^{-}$counterions, respectively. From the synthesis of the [2]rotaxane $\mathbf{1 . 4 P F}_{6}$, a [3] rotaxane was obtained as a by-product, which was isolated and characterized by ESI-MS revealing (see Figure S1 in the Supporting Information) the peaks at $\mathrm{m} / \mathrm{z}$ 1409 and 891, corresponding to the loss of two and three $\mathrm{PF}_{6}{ }^{-}$counterions, respectively.

${ }^{1}$ H NMR spectroscopic investigations: A good indication of the formation of the [2] rotaxane containing NP units and the $\mathrm{CBPQT}^{4+}$ ring are the signals for the two peri protons $\left(H_{4}\right.$ and $\left.H_{8}\right)$ on the NP unit, which are shifted upfield significantly at $298 \mathrm{~K}$ compared with those observed for the dumbbell compound $\mathbf{3}$, on account of $[\mathrm{C}-\mathrm{H} \cdots \pi]$ interactions ${ }^{[19]}$ between the encircled NP unit and the two $p$-xylylene links in the $\mathrm{CBPQT}^{4+}$ ring. Usually, the signals of the two peri protons are found at $\delta \approx 2-4 \mathrm{ppm}$ in flexible ${ }^{[20]}$ rotaxanes incorporating polyethyleneglycol linkers between the two NP units and in non-degenerate (bistable) rigid ${ }^{[10]}$ rotaxane systems incorporating an MPTTF and an NP unit with phenylacetylene linker in their dumbbell components.

In the rigid and degenerate [2] rotaxanes $1.4 \mathrm{PF}_{6}$ and 2.4 $\mathrm{PF}_{6}$, however, the two peri proton peaks for the $\mathrm{CBPQT}^{4+}$-encircled NP unit were not found at $\delta \approx 3 \mathrm{ppm}$ at 298 K. Instead, they were located (Table 1 and Figure 2) at $\delta \approx 6 \mathrm{ppm}$, a chemical shift which was confirmed by 2D COSY and ROESY NMR spectra (see Figures S3-S9 in the Supporting Information). This observation is consistent with a much weaker binding of an oxyethynyl-NP unit as compared to a dioxy-NP unit. The enthalpic contribution to the binding free energy is dwarfed by the entropic gain from the higher degrees of freedom that the ring experiences when it is not encircling an NP unit. Consequently, the two peri proton peaks were found at $\delta \approx 3 \mathrm{ppm}$ in both [2] rotaxanes 1.4 $\mathrm{PF}_{6}$ and $2.4 \mathrm{PF}_{6}$ with aid of $2 \mathrm{D}$ COSY and ROESY NMR spectra at low temperatures. This observation suggests that there is a thermodynamic balance between the enthalpic $(\Delta H)$ and entropic $(T \Delta S)$ components to the free energy where, at low temperatures, enthalpy takes over, whereas at higher temperatures, entropy dominates. This situation rep-

Table 1. ${ }^{1} \mathrm{H}$ NMR $(500 \mathrm{MHz})$ spectroscopic data for the [2]rotaxanes $\mathbf{1} \cdot 4 \mathrm{PF}_{6}$ and $\mathbf{2} \cdot 4 \mathrm{PF}_{6}$ and their chemical shift differences $(\Delta \delta)$ compared with reference to their dumbbell components in $\mathrm{CD}_{3} \mathrm{COCD}_{3}$ at $298 \mathrm{~K}$.

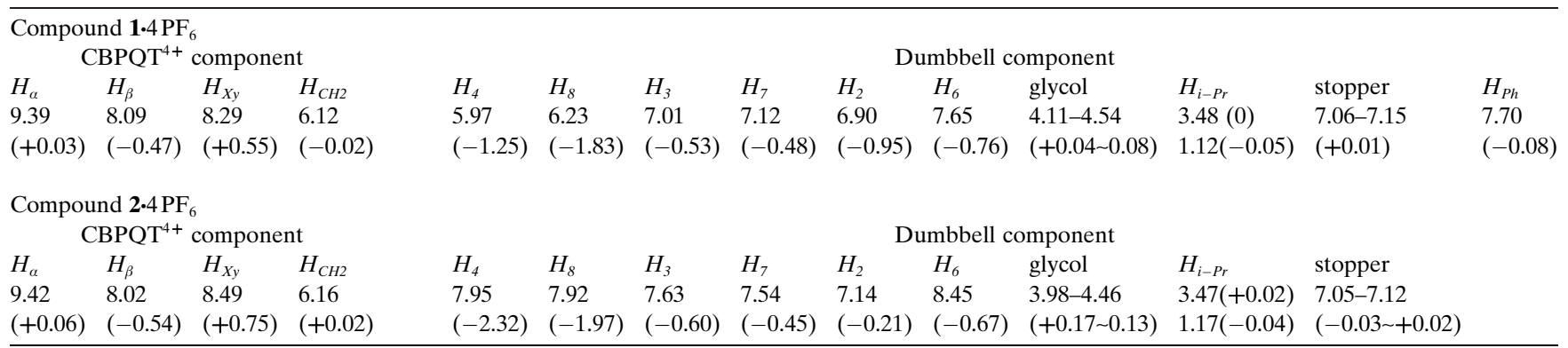



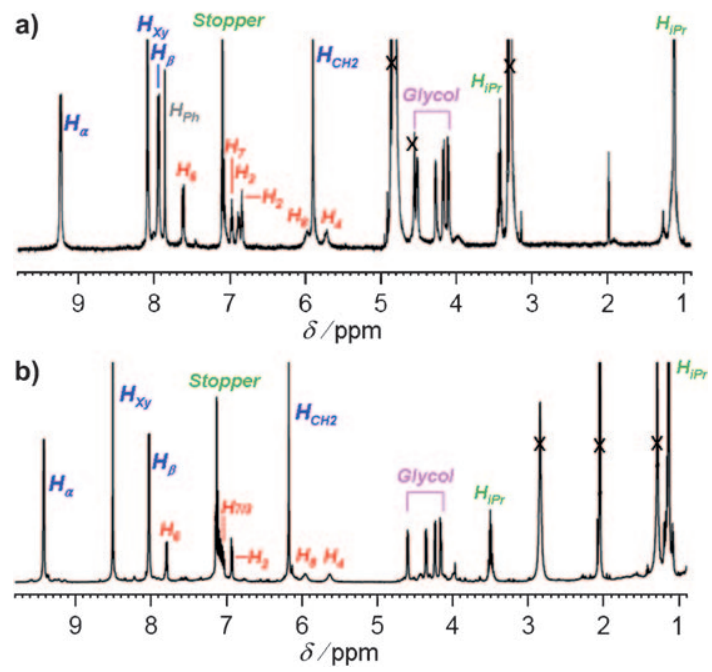

Figure 2. ${ }^{1} \mathrm{H}$ NMR spectra of the [2] rotaxanes a) $1 \cdot 4 \mathrm{PF}_{6}$ in $\mathrm{CD}_{3} \mathrm{OD}$ and b) $2.4 \mathrm{PF}_{6}$ in $\mathrm{CD}_{3} \mathrm{COCD}_{3}$ at $298 \mathrm{~K}$. The protons are defined alongside the structural formula in Scheme 2.

resents a perfect scenario for a molecular thermal switch, where the $\mathrm{CBPQT}^{4+}$ ring shuttles constantly from one station to the other. At low temperatures, the ring spends more of its time on the NP units, but as the temperature is increased, the ring resides less and less of the time on the NP units, effectively becoming a "roving ambassador" along the whole length of the dumbbell component.

The ${ }^{1} \mathrm{H}$ NMR spectra of the [2] rotaxanes $\mathbf{1 . 4}^{-} \mathrm{PF}_{6}$ (Figure $2 \mathrm{a}$ ) in $\mathrm{CD}_{3} \mathrm{OD}$ and $\mathbf{2} \cdot 4 \mathrm{PF}_{6}$ (Figure $2 \mathrm{~b}$ ) in $\mathrm{CD}_{3} \mathrm{COCD}_{3}$ recorded at $298 \mathrm{~K}$ provide overwhelming evidence for the formation of the [2] rotaxanes. The signals for some key protons in both $1.4 \mathrm{PF}_{6}$ and $2 \cdot 4 \mathrm{PF}_{6}$ recorded in $\mathrm{CD}_{3} \mathrm{COCD}_{3}$ are shifted considerably as compared with those in the $\mathrm{CBPQT}^{4+}$ ring and the dumbbell-shaped compounds (Table 1). The two peri proton peaks on the NP units in $1.4 \mathrm{PF}_{6}$ were located at $\delta=5.97$ and $6.23 \mathrm{ppm}$ and so are shifted upfield ( $\Delta \delta=1.25$ and $1.83 \mathrm{ppm}$, respectively) in $\mathrm{CD}_{3} \mathrm{COCD}_{3}$ at $298 \mathrm{~K}$ with respect to the corresponding signals in the dumbbell. Similarly, the two peri proton peaks in $2 \cdot 4 \mathrm{PF}_{6}$ were located at $\delta=5.63$ and $5.95 \mathrm{ppm}$ and so are shifted upfield $(\Delta \delta=2.32$ and $1.97 \mathrm{ppm}$, respectively) in $\mathrm{CD}_{3} \mathrm{COCD}_{3}$ at $298 \mathrm{~K}$, once again with respect to the dumbbell. Furthermore, the two peri proton peaks exhibit broadening, while the other protons on the NP units produce sharp peaks, a fact which may be attributable to the molecular shuttling of the $\mathrm{CBPQT}^{4+}$ ring between the two NP units.

Dynamic ${ }^{1} \mathrm{H}$ NMR spectroscopy was performed in $\mathrm{CD}_{3} \mathrm{COCD}_{3}$ to quantify the shuttling barrier for the $\mathrm{CBPQT}^{4+}$ ring travelling along the rigid rod between the two NP units in the [2] rotaxane $\mathbf{1 . 4} \mathrm{PF}_{6}$. This barrier plays an important role in relation to the bistable rotaxane's performance in device settings. ${ }^{[3,4]}$ The kinetic and thermodynamic parameters for the dynamic processes observed in both $\mathbf{1 . 4} \mathrm{PF}_{6}$ and $\mathbf{2} \cdot 4 \mathrm{PF}_{6}$ are listed in Tables 2 and 3, respectively.
Table 2. Kinetic and thermodynamic data ${ }^{[a]}$ for the shuttling behavior of the $\mathrm{CBPQT}^{4+}$ ring between the NP units in the [2] rotaxane $1.4 \mathrm{PF}_{6}$ using the coalescence method ( $T_{\mathrm{c}}=$ coalescence temperature, $\Delta v=$ limiting chemical shift difference, $k_{\mathrm{ex}}=$ rate constant).

\begin{tabular}{lllll}
\hline Probe $\mathrm{H}$ & $\begin{array}{l}T_{\mathrm{c}} \\
{[\mathrm{K}]^{[\mathrm{b}]}}\end{array}$ & $\begin{array}{l}\Delta v \\
{[\mathrm{~Hz}]}\end{array}$ & $\begin{array}{l}k_{\mathrm{ex}} \\
{\left[\mathrm{s}^{-1}\right]}\end{array}$ & $\begin{array}{l}\Delta G_{\mathrm{c}}{ }^{+} \\
{\left[\mathrm{kcal} \mathrm{mol}^{-1}\right]}\end{array}$ \\
\hline$\alpha$-BIPY $^{2+[\mathrm{c}]}$ & 208 & 160 & $355 \pm 1$ & $9.6 \pm 0.1$ \\
bismethylene $^{[\mathrm{d}]}$ & 208 & 54 & $119 \pm 1$ & $10.0 \pm 0.1$ \\
\hline
\end{tabular}

[a] ${ }^{1} \mathrm{HNMR}$ spectrum recorded at $500 \mathrm{MHz}$ in $\mathrm{CD}_{3} \mathrm{COCD}_{3}$ solution. [b] Calibrated by using neat $\mathrm{MeOH}$ sample. [c] The $\alpha$-BIPY ${ }^{2+}$ protons on the $\mathrm{CBPQT}^{4+}$ ring used to probe the energy barrier. [d] The bismethylene protons on the glycol chains in the dumbbell-shaped component used to probe the energy barrier.

The VT ${ }^{1} \mathrm{H}$ NMR spectra of $\mathbf{1 . 4} \mathrm{PF}_{6}$ is shown in Figure 3 and the data are summarized in Table 2 . The ${ }^{1} \mathrm{H}$ NMR spectrum at $187 \mathrm{~K}$ features four broad peaks in the region associated with $\alpha$-bipyridinium (BIPY ${ }^{2+}$ ) protons (in pale blue stripe) on the $\mathrm{CBPQT}^{4+}$ ring. With increasing temperature, these broad peaks coalesce into one broad peak $(\delta$ $\approx 9.5 \mathrm{ppm})$ at $208 \mathrm{~K}$. These spectral changes correspond to a free energy of activation $\left(\Delta G_{\mathrm{c}}{ }^{\mp}\right)^{[21]}$ of $9.6 \mathrm{kcal} \mathrm{mol}^{-1}$, ${ }^{[10]} \mathrm{a}$ value which was found to be significantly lower than that $\left(13.0-15.0 \mathrm{kcal} \mathrm{mol}^{-1}\right)$ found previously ${ }^{[20]}$ for other more flexible molecular shuttles. Similarly, the bismethylene protons (in pale pink stripe) on the glycol chains were used to probe the shuttling process and the coalescence data were calculated, leading to a $\Delta G_{\mathrm{c}}{ }^{\neq}$value of $10.0 \mathrm{kcal} \mathrm{mol}^{-1}$. The methine protons (in pale green stripe) on the isopropyl groups were not used to probe the shuttling process because there was no separation of their signals at the low temperatures.

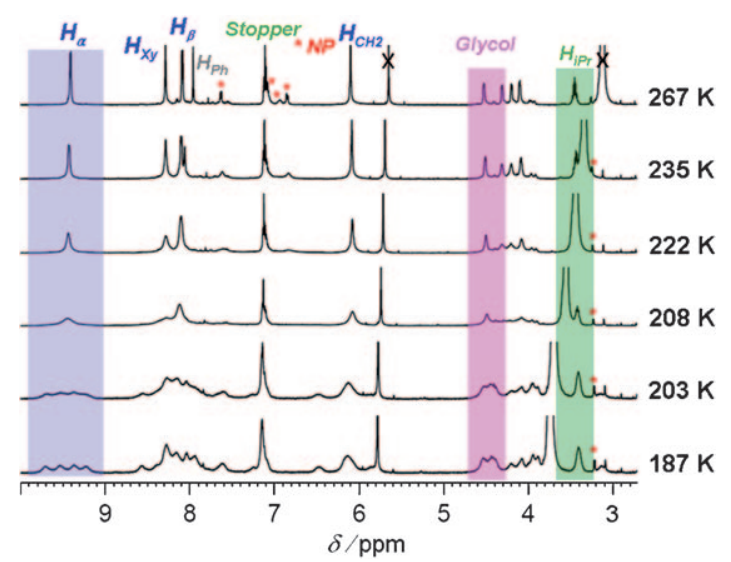

Figure 3. Partial VT ${ }^{1} \mathrm{H}$ NMR spectra of $1.4 \mathrm{PF}_{6}$ in $\mathrm{CD}_{3} \mathrm{COCD}_{3}$.

The VT ${ }^{1} \mathrm{H}$ NMR spectra of $2 \cdot 4 \mathrm{PF}_{6}$ is shown in Figure 4 and the relevant data are summarized in Table 3 . The $\alpha$-protons on the $\mathrm{BIPY}^{2+}$ unit of the $\mathrm{CBPQT}^{4+}$ ring, the methine on the isopropyl stoppers, and the bismethylene protons on the glycol chains in the dumbbell-shaped component in $2 \cdot 4 \mathrm{PF}_{6}$ were used to probe the energy barrier, resulting in similar free energies of activation $\left(\Delta G_{\mathrm{c}}{ }^{*}\right)$ of $10.3,9.5$, and 
Table 3. Kinetic and thermodynamic data ${ }^{[a]}$ for the shuttling behavior of the $\mathrm{CBPQT}^{4+}$ ring between the NP units in the [2] rotaxane $2 \cdot 4 \mathrm{PF}_{6}$ using the coalescence method ( $T_{\mathrm{c}}=$ coalescence temperature, $\Delta v=$ limiting chemical shift difference, $k_{\text {ex }}=$ rate constant).

\begin{tabular}{lllll}
\hline Probe $\mathrm{H}$ & $\begin{array}{l}T_{\mathrm{c}} \\
{[\mathrm{K}]^{[\mathrm{b}]}}\end{array}$ & $\begin{array}{l}\Delta v \\
{[\mathrm{~Hz}]}\end{array}$ & $\begin{array}{l}k_{\mathrm{ex}} \\
{\left[\mathrm{s}^{-1}\right]}\end{array}$ & $\begin{array}{l}\Delta G_{\mathrm{c}}{ }^{+} \\
{\left[\mathrm{kcal} \mathrm{mol}^{-1}\right]}\end{array}$ \\
\hline$\alpha-\mathrm{BIPY}^{2+[\mathrm{c}]}$ & 225 & 211 & $469 \pm 1$ & $10.3 \pm 0.1$ \\
methine $^{[\mathrm{d}]}$ & 196 & 38 & $85 \pm 1$ & $9.5 \pm 0.1$ \\
bismethylene $^{[\mathrm{e}]}$ & 214 & 59 & $131 \pm 1$ & $10.3 \pm 0.1$ \\
\hline
\end{tabular}

[a] ${ }^{1} \mathrm{H} N M R$ spectrum recorded at $500 \mathrm{MHz}$ in $\mathrm{CD}_{3} \mathrm{COCD}_{3}$ solution. [b] Calibrated by using neat $\mathrm{MeOH}$ sample. [c] The $\alpha$-BIPY ${ }^{2+}$ protons on the $\mathrm{CBPQT}^{4+}$ ring used to probe the energy barrier. [d] The methine protons on the isopropyl stoppers in the dumbbell-shaped component used to probe the energy barrier. [e] The bismethylene protons in the glycol chains in the dumbbell-shaped component used to probe the energy barrier.

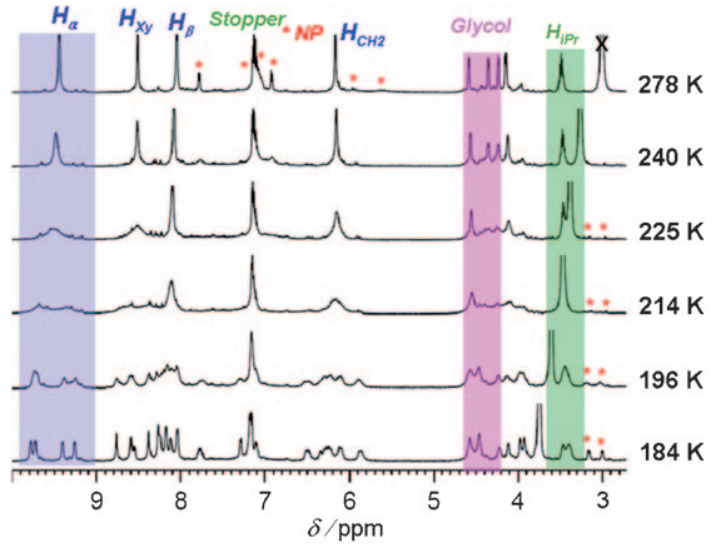

Figure 4. Partial VT ${ }^{1} \mathrm{H}$ NMR spectra of $\mathbf{2} \cdot 4 \mathrm{PF}_{6}$ in $\mathrm{CD}_{3} \mathrm{COCD}_{3}$.

$10.3 \mathrm{kcal} \mathrm{mol}^{-1}$, respectively. Interestingly, these $\Delta G_{\mathrm{c}}{ }^{\neq}$values match exactly those observed for the [2] rotaxane $\mathbf{1} \cdot 4 \mathrm{PF}_{6}$. Consequently, the different length of the linkers in the dumbbell components of the two [2]rotaxanes are not reflected directly in the heights of the energy barriers.

X-ray crystallographic investigation: Slow evaporation of a $\mathrm{MeCN} / \mathrm{CH}_{2} \mathrm{Cl}_{2} / \mathrm{C}_{6} \mathrm{H}_{14} / i \mathrm{Pr}_{2} \mathrm{O}$ solution of $\mathbf{3}$ yielded colorless platelet-shaped, single crystals suitable for X-ray crystallography. In the solid-state, 3 adopts (Figure 5) a non-centrosymmetric geometry. The total length of the molecule is $3.6 \mathrm{~nm}$ and the distance covered by the ethynyl-PH-ethynyl unit as the spacer between two NP units is $8.1 \AA$, with an S-

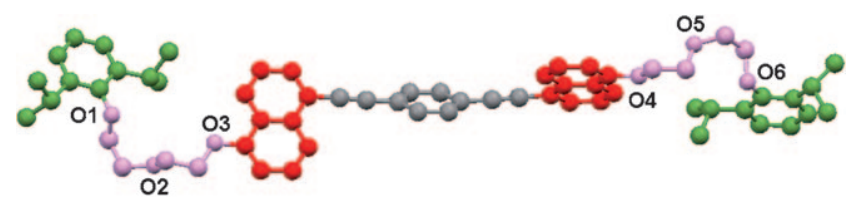

Figure 5. Solid-state structure of the compound 3. The hydrogen atoms are omitted for the sake of clarity. Color code: the ethynyl-PH-ethynyl unit: gray; the NP units: red; the diethyleneglycol chains: pink; 2,6-diisopropylphenyl units: green. shaped backbone overall in which dihedral angles of $134^{\circ}$ and $34^{\circ}$ are evident with respect to the central $\mathrm{PH}$ ring. It would appear that stabilization of the molecule is achieved by a combination of a) intermolecular $[\mathrm{C}-\mathrm{H} \cdots \mathrm{O}]$ interactions $^{[22]}$ (see Figure S13 in the Supporting Information) between the three oxygen atoms in the diethyleneglycol chains and appropriate protons in the diethyleneglycol chains and the $\mathrm{PH}$ centers, and b) intermolecular $[\mathrm{C}-\mathrm{H} \cdots \pi]$ interactions (see Figure S13 in the Supporting Information) between the NP units and the protons in the diethyleneglycol chains of the neighboring molecules, the NP units and the protons in the NP units of the neighboring molecules, as well as the benzene rings in the stoppers and the protons in the NP units of the neighboring molecules.

The solid-state structures of the molecular shuttle $2 \cdot 4 \mathrm{PF}_{6}$ and its free dumbbell-shaped molecule were reported ${ }^{[11]}$ recently. The structure of $\mathbf{2} \cdot 4 \mathrm{PF}_{6}$ shows an interdigitated superstructure with the molecules of this [2]rotaxane lining themselves up in parallel $\pi-\pi$ stacks $^{[23]}$ of alternating NP ring systems and the BIPY ${ }^{2+}$ units, exhibiting a well-organized donor-acceptor recognition motif. In the structure of the free dumbbell-shaped molecule, the total length of the molecule is $3.1 \mathrm{~nm}$ and the distance covered by the butadiyne unit as the rod between the two NP units is $3.8 \AA$, which is less than half that in $\mathbf{3}$ containing the ethynyl-PHethynyl rod.

Molecular simulations investigation: To understand the nature of the weak forces that govern the extended and highly ordered $\pi-\pi$ stacking in the superstructure, as well as in the shuttling exhibited by compounds $1.4 \mathrm{PF}_{6}$ and $2 \cdot 4 \mathrm{PF}_{6}$, we calculated their molecular structures utilizing the DREIDING force field. ${ }^{[16]}$ This force field has been used ${ }^{[24]}$ for the accurate description of structural and dynamic parameters in mechanically interlocked molecules, in conjunction with the charge equilibration $(\mathrm{QEq})$ method, ${ }^{[25]}$ as implemented in the Lingraf ${ }^{[26]}$ software suite [release 3.23]. The DREIDING force field is a full atomistic generic force field. Figure 6 shows the overlay of the X-ray structure in the darker colors and the DREIDING minimized $(0 \mathrm{~K})$ structure of $2.4 \mathrm{PF}_{6}$ in the paler colors. The structure was obtained by minimization of a periodic system using the crystallographic data as input. There are similarities and differences between the experimental and calculated geometries to the extent that those regions in the superstructure where intramolecular forces at work are described with higher fi-

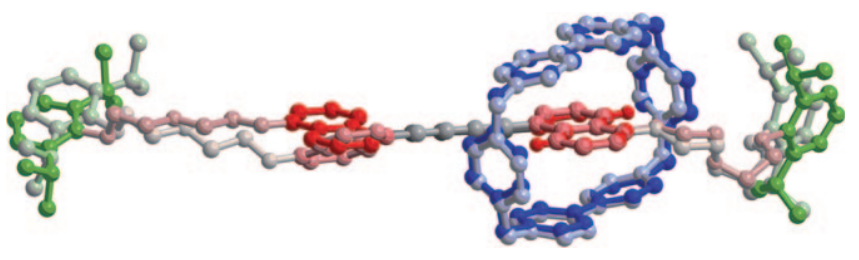

Figure 6. Overlay of the calculated and experimental (solid-state) structures of $\mathbf{2} \cdot 4 \mathrm{PF}_{6}$. The X-ray crystal structure is displayed in darker colors and the DREIDING-minimized structure is overlayed in paler colors. 
delity than those in which intramolecular forces dominate the superstructure. The variance in the dihedral angle between the NP rings in $2.4 \mathrm{PF}_{6}$ is also a consequence of the lack of parametrization for the extended $\pi$-delocalized butadiyne linking both aromatic systems. Next, we examined the geometry of a single molecule in order to estimate the barriers to shuttling of the $\mathrm{CBPQT}^{4+}$ ring in $1.4 \mathrm{PF}_{6}$ and $\mathbf{2 \cdot 4} \mathrm{PF}_{6}$. Using a manually steered ${ }^{[27]}$ combination of $\mathrm{MM}$ and $\mathrm{MD}$ at $0 \mathrm{~K}$ and $300 \mathrm{~K}$, respectively, we calculated ${ }^{[28]}$ a shuttling energy barrier of $10.4 \mathrm{kcal} \mathrm{mol}^{-1}$ for both $\mathbf{1} \cdot 4 \mathrm{PF}_{6}$ and $2 \cdot 4 \mathrm{PF}_{6}$ which is in reasonably good agreement with the experimental values ${ }^{[10]}$ of 9.6 and $10.3 \mathrm{kcal} \mathrm{mol}^{-1}$ for $\mathbf{1 . 4} \mathrm{PF}_{6}$ and $\mathbf{2} \cdot 4 \mathrm{PF}_{6}$, respectively. The calculated structure of $1.4 \mathrm{PF}_{6}$ using the DREIDING force field shown in Figure 7, adopts encircled rigid and degenerate molecular shuttle containing an enlarged spacer between the two NPs in the [2]rotaxane formation.

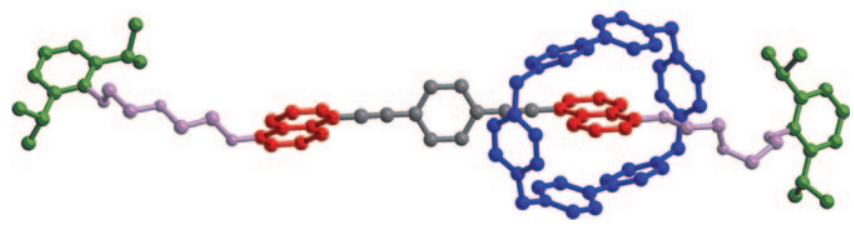

Figure 7. The DREIDING-minimized structure of $1 \cdot 4 \mathrm{PF}_{6}$. The hydrogen atoms are omitted for the sake of clarity. Color code: the ethynyl-PHethynyl unit: gray; the NP units: red; the diethyleneglycol chains: pink; the 2,6-diisopropylphenyl units: green; the $\mathrm{CBPQT}^{4+}$ ring: blue.

The fact that DREIDING predicts virtually identical shuttling barriers for $1.4 \mathrm{PF}_{6}$ and $2.4 \mathrm{PF}_{6}$ is not surprising, since the activation energy is associated with the slipping and deslipping of the $\mathrm{CBPQT}^{4+}$ ring from the highly organized arrangement when situated on an NP unit. For both $1.4 \mathrm{PF}_{6}$ and $2.4 \mathrm{PF}_{6}$, while the $\mathrm{CBPQT}^{4+}$ ring is encircling around the NP units, it experiences the same relative environment. This observation suggests that the stereoelectronic characteristics of only the first few linker atoms play a role in determining the shuttling rate. This phenomenon has also been observed $^{[20]}$ in the series of degenerate shuttles with 1,5dioxy-NP ring systems with highly varied intermediate linkers where the shuttling barrier did not vary more than $0.4 \mathrm{kcal} \mathrm{mol}^{-1}$ away from $15.4 \mathrm{kcal} \mathrm{mol}^{-1}$.

\section{Conclusions}

In conclusion, two rigid and degenerate molecular shuttles have been investigated in considerable detail. The new [2] rotaxane $\left(1.4 \mathrm{PF}_{6}\right)$ was synthesized by using the templatedirected protocol of clipping under high-pressure conditions, and was characterized by a combination of NMR spectroscopy and ESI-MS spectrometry. The formation of both [2] rotaxanes was confirmed by the shifts in the proton signals of the [2]rotaxanes, relative to those in the free components, especially the two peri proton signals on the NP units since they are key signals which are shifted significantly upfield at low temperatures. Interestingly, the same signals exhibited a moderate upfield shift at $298 \mathrm{~K}$, something which has never been observed in this kind of molecular shuttle. The VT ${ }^{1} \mathrm{H}$ NMR spectroscopy experiments were performed to obtain kinetic and thermodynamic data. The $\alpha$-BIPY ${ }^{2+}$, methine, and bismethylene protons were used to probe the shuttling behavior, resulting in very similar energy barriers in the two molecular shuttles. The shuttling energy barriers calculated by the coalescence method at low temperatures are lower than those for other more flexible rotaxanes, as well as non-degenerate (bistable) rigid rotaxanes. The $\mathrm{CBPQT}^{4+}$ ring in the rigid molecular shuttles moves back and forth between the two NP units in solution at a rate of around $560000-570000(0.6$ at $199 \mathrm{~K})$ times per second at room temperature. The solid-state structure of the rigid dumbbell-shaped compound $\mathbf{3}$ shows clearly the fully rigid backbone which allows for the fast shuttling process in the [2]rotaxane. The different lengths of the spacers between two NP units in the two rotaxanes were not reflected directly in the height of the energy barrier between the two NP sites. These results could be useful for the growth in the fundamental understanding of molecular shuttles in rigid molecular systems, as well as for developing devices having structural and functional rigidity advantages in condensed phases.

\section{Experimental Section}

General: All reagents were purchased from Aldrich and used without further purification. The rotaxane $\mathbf{2} \cdot 4 \mathrm{PF}_{6}$ was prepared according to the previous reports. ${ }^{[10,11]} 2$-(2-(2,6-Diisopropylphenoxy)ethoxy)ethanol (4), ${ }^{[10]}$ 5-iodonaphthol (6), ${ }^{[10]} 1,1^{\prime}$-[1,4-phenylenebis(methylene) $]$ bis-4,4'-bipyridinium bis(hexafluorophosphate) $\left(\mathbf{8} \cdot 2 \mathrm{PF}_{6}\right),{ }^{[16]}$ and cyclobis(paraquat- $p$ phenylene) tetrakis(hexafluorophosphate) $\left(\mathrm{CBPQT} \cdot 4 \mathrm{PF}_{6}\right)^{[5]}$ were prepared according to literature procedures. High-pressure reactions were carried out in a custom-made Teflon container under $12 \mathrm{kbar}$ of pressure generated by a Psika high-pressure apparatus. Thin layer chromatography (TLC) was performed on silica gel 60 F254 (E. Merck). The plates were inspected by UV light and, if required, developed in $I_{2}$ vapor. Column chromatography was performed on silica gel 60F (Merck 9385, 0.040$0.063 \mathrm{~mm}$ ) or alumina (J. T. Baker, $0.050-0.200 \mathrm{~mm}$ ). Melting points were recorded on an Electrothermal 9100 instrument in open capillary tubes and are uncorrected. Routine nuclear magnetic resonance (NMR) spectra were recorded at $25^{\circ} \mathrm{C}$ on a Brüker Avance 500 spectrometer, with working frequencies of $500 \mathrm{MHz}$ for ${ }^{1} \mathrm{H}$, and $125 \mathrm{MHz}$ for ${ }^{13} \mathrm{C}$ nuclei. Chemical shifts are quoted in ppm on the $\delta$ scale and coupling constants $(J)$ are expressed in Hertz $(\mathrm{Hz})$. Samples for ${ }^{1} \mathrm{H}$ NMR spectroscopic studies were prepared using solvents purchased from Cambridge Isotope Labs. VT-NMR spectra were recorder on a Brüker Avance 500 spectrometer and temperatures were calibrated with a neat $\mathrm{MeOH}$ sample before or after each experiment and assumed to remain constant during the experiment. All spectra were referenced using the residual solvent peak. The full assignment of the ${ }^{1} \mathrm{H}$ NMR signals was performed using $2 \mathrm{D}$ COSY (correlation spectroscopy) and ROESY (rotating-frame Overhauser enhancement spectroscopy) experiments. Matrix-assisted laser-desorption/ionization time-off-light mass spectrometry (MALDI-TOF MS) was performed on an IonSpec 4.7 tesla Ultima Fourier Transform mass spectrometer, utilizing a 2,5-dihydroxybenzoic acid (DHB) matrix. Fast atom bombardment mass spectra were obtained on a JEOL JMS-600H high resolution mass spectrometer equipped with a FAB probe. Electro- 
spray ionization mass spectra (ESI-MS) were measured on an IonSpec FTICR mass spectrometer with $\mathrm{CH}_{3} \mathrm{COCH}_{3}$ as the mobile phase.

2-[2-(2,6-Diisopropylphenoxy)ethoxy]ethyl 4-methylbenzenesulfonate (5): 2-[2-(2,6-Diisopropylphenoxy)ethoxy] ethanol 4 (1.0 g, $3.75 \mathrm{mmol}), p$ toluenesulfonyl chloride $(0.86 \mathrm{~g}, 4.51 \mathrm{mmol})$, and dimethylaminopyridine (DMAP) $(100 \mathrm{mg})$ were dissolved in anhydrous $\mathrm{CH}_{2} \mathrm{Cl}_{2}(50 \mathrm{~mL})$ and $\mathrm{Et}_{3} \mathrm{~N}(2 \mathrm{~mL})$, and the reaction mixture was stirred for one day. The solvent was evaporated, and extracted with $\mathrm{CH}_{2} \mathrm{Cl}_{2}$, washed with $\mathrm{H}_{2} \mathrm{O}$ before the solvent was evaporated and the residue purified by column chromatography $\left(\mathrm{SiO}_{2}\right.$ : EtOAc/hexane 1:5) to afford 5 as a white solid $(1.37 \mathrm{~g}, 87 \%)$. 5: m.p. $40-42{ }^{\circ} \mathrm{C} ;{ }^{1} \mathrm{H}$ NMR $\left(500 \mathrm{MHz}, \mathrm{CDCl}_{3}, 25^{\circ} \mathrm{C}\right.$ TMS): $\delta=7.83(\mathrm{~d}, J=8 \mathrm{~Hz}, 2 \mathrm{H}), 7.35(\mathrm{~d}, J=8 \mathrm{~Hz}, 2 \mathrm{H}), 7.10(\mathrm{~s}, 3 \mathrm{H}), 4.23$ $(\mathrm{t}, J=5 \mathrm{~Hz}, 2 \mathrm{H}), 3.86(\mathrm{t}, J=5 \mathrm{~Hz}, 2 \mathrm{H}), 3.82-3.78(\mathrm{~m}, 4 \mathrm{H}), 3.33$ (sep, $J=$ $7 \mathrm{~Hz}, 2 \mathrm{H}), 2.44(\mathrm{~s}, \quad 3 \mathrm{H}), 1.21 \mathrm{ppm}(\mathrm{d}, J=7 \mathrm{~Hz}, 12 \mathrm{H}) ;{ }^{13} \mathrm{C} \mathrm{NMR}$ $\left(100 \mathrm{MHz}, \mathrm{CDCl}_{3}, 25^{\circ} \mathrm{C}, \mathrm{TMS}\right): \delta=152.9,144.8,141.8,129.8,129.1$, 128.0, 124.7, 124.0, 73.7, 70.7, 69.3, 69.0, 26.2, 24.1, 21.6 ppm; HRMS: calcd for $\mathrm{C}_{23} \mathrm{H}_{32} \mathrm{O}_{5} \mathrm{~S}\left([M]^{+}\right) 420.1970$, found 420.1980; MALDI-TOF MS: $m / z: 420[M]^{+}$

\section{5-(2-\{4-[2-(5-Hydroxynaphthalen-1-yl)ethynyl]phenyl]ethynyl)naphtha-}

len-1-ol (7): 5-Iodonaphthol 6 (1.4 g, $5.41 \mathrm{mmol})$, 1,4-diethynylbenzene $(0.31 \mathrm{~g}, 2.46 \mathrm{mmol}),\left[\mathrm{PdCl}_{2}\left(\mathrm{PPh}_{3}\right)_{2}\right](89 \mathrm{mg}, 0.127 \mathrm{mmol}), \mathrm{CuI}(47 \mathrm{mg}$, $0.247 \mathrm{mmol})$, and $\mathrm{PPh}_{3}(60 \mathrm{mg}, 0.229 \mathrm{mmol})$ were dissolved in $\mathrm{Et}_{3} \mathrm{~N}$ $(30 \mathrm{~mL})$ and $\mathrm{MeCN}(10 \mathrm{~mL})$, causing a color change to a dark brown, before being heated under reflux for $4 \mathrm{~h}$. After extraction with $\mathrm{CH}_{2} \mathrm{Cl}_{2}$, the solvent was evaporated and the residue was purified by column chromatography $\left(\mathrm{SiO}_{2}: \mathrm{MeOH} / \mathrm{CH}_{2} \mathrm{Cl}_{2}, 1: 50\right)$ to afford $\mathbf{7}$ as a colorless solid $(0.90 \mathrm{~g}, \quad 90 \%) . \quad 7: \quad$ m.p. $\approx 213^{\circ} \mathrm{C} \quad$ (decomp); ${ }^{1} \mathrm{H} \mathrm{NMR} \quad(500 \mathrm{MHz}$, $\left.\mathrm{CD}_{3} \mathrm{COCD}_{3}, 25^{\circ} \mathrm{C}, \mathrm{TMS}\right): \delta=9.26(\mathrm{br}, 2 \mathrm{H}), 8.31(\mathrm{~d}, J=8 \mathrm{~Hz}, 2 \mathrm{H}), 7.95$ (d, $J=8 \mathrm{~Hz}, 2 \mathrm{H}), 7.79(\mathrm{~d}, J=8 \mathrm{~Hz}, 2 \mathrm{H}), 7.73(\mathrm{~s}, 4 \mathrm{H}), 7.48(\mathrm{t}, J=8 \mathrm{~Hz}$, $2 \mathrm{H}), 7.46(\mathrm{t}, J=8 \mathrm{~Hz}, 2 \mathrm{H}), 7.01 \mathrm{ppm}(\mathrm{d}, J=8 \mathrm{~Hz}, 2 \mathrm{H}) ;{ }^{13} \mathrm{C} \mathrm{NMR}$ $\left(125 \mathrm{MHz}, \mathrm{CD}_{3} \mathrm{COCD}_{3}, 25^{\circ} \mathrm{C}\right.$, TMS $): \delta=153.5,134.3,131.6,130.8,127.4$, 124.7, 124.0, 123.4, 123.2, 119.8, 116.9, 108.8, 93.4, 89.7 ppm; HRMS: calcd for $\mathrm{C}_{30} \mathrm{H}_{18} \mathrm{O}_{2}\left([M]^{+}\right) 410.1307$, found 410.1303 .

1,4-Bis[2-(5-\{2-[2-(2,6-diisopropylphenoxy)ethoxy]ethoxy\}naphthalen-1yl)ethynyl]benzene (3): Compounds $5(0.74 \mathrm{~g}, 1.76 \mathrm{mmol}), 7(0.3 \mathrm{~g}$, $0.731 \mathrm{mmol})$, and $\mathrm{K}_{2} \mathrm{CO}_{3}(0.4 \mathrm{~g}, 2.89 \mathrm{mmol})$ were dissolved in anhydrous $\mathrm{MeCN}(80 \mathrm{~mL})$, before being heated under reflux for three days. The solvent was evaporated, and extracted with $\mathrm{CH}_{2} \mathrm{Cl}_{2}$, washed with $\mathrm{H}_{2} \mathrm{O}$ before the solvent was evaporated and the residue was purified by column chromatography $\left(\mathrm{SiO}_{2}: \mathrm{CH}_{2} \mathrm{Cl}_{2}\right.$ /hexane $\left.1: 2\right)$ to afford $\mathbf{3}$ as a colorless solid $(0.33 \mathrm{~g}, 50 \%)$. 3: m.p. $108-110^{\circ} \mathrm{C} ;{ }^{1} \mathrm{H}$ NMR $\left(500 \mathrm{MHz}, \mathrm{CDCl}_{3}\right.$, $\left.25^{\circ} \mathrm{C}, \mathrm{TMS}\right): \delta=8.37(\mathrm{~d}, J=8 \mathrm{~Hz}, 2 \mathrm{H}), 8.04(\mathrm{~d}, J=8 \mathrm{~Hz}, 2 \mathrm{H}), 7.79(\mathrm{~d}$, $J=8 \mathrm{~Hz}, 2 \mathrm{H}), 7.67(\mathrm{~s}, 4 \mathrm{H}), 7.52(\mathrm{t}, J=8 \mathrm{~Hz}, 2 \mathrm{H}), 7.46(\mathrm{t}, J=8 \mathrm{~Hz}, 2 \mathrm{H})$, $7.11(\mathrm{~s}, 6 \mathrm{H}), 6.94(\mathrm{~d}, J=8 \mathrm{~Hz}, 2 \mathrm{H}), 4.40(\mathrm{t}, J=5 \mathrm{~Hz}, 4 \mathrm{H}), 4.13(\mathrm{t}, J=$ $5 \mathrm{~Hz}, 4 \mathrm{H}), 4.03-3.98(\mathrm{~m}, 8 \mathrm{H}), 3.42(\mathrm{sep}, J=7 \mathrm{~Hz}, 4 \mathrm{H}), 1.21 \mathrm{ppm}(\mathrm{d}, J=$ $7 \mathrm{~Hz}, 24 \mathrm{H}) ;{ }^{13} \mathrm{C}$ NMR $\left(125 \mathrm{MHz}, \mathrm{CDCl}_{3}, 25^{\circ} \mathrm{C}, \mathrm{TMS}\right): \delta=154.8,153.0$, $141.8,134.3,131.5,131.0,126.8,125.5,124.6,124.5,124.0,123.2,123.2$, $120.1,118.6,105.5,93.8,89.8,73.9,70.8,70.0,68.1,26.2,24.0 \mathrm{ppm}$; HRMS: calcd for $\mathrm{C}_{62} \mathrm{H}_{67} \mathrm{O}_{6}\left([M+\mathrm{H}]^{+}\right) 907.4938$, found 907.4805 , calcd for $\mathrm{C}_{62} \mathrm{H}_{66} \mathrm{KO}_{6}\left([M+\mathrm{K}]^{+}\right)$945.4496, found 945.4279; MALDI-TOF MS: $\mathrm{m} / \mathrm{z}: 906[\mathrm{M}]^{+}$

Molecular shuttle 1.4PF : The dumbbell compound 3 (100 mg, $0.11 \mathrm{mmol}), 8 \cdot 2 \mathrm{PF}_{6}(780 \mathrm{mg}, 1.10 \mathrm{mmol})$, and dibromo- $p$-xylene $(291 \mathrm{mg}$, $1.10 \mathrm{mmol}$ ) were dissolved in anhydrous DMF $(8 \mathrm{~mL})$, forming a reddishbrown solution. The reaction mixture was subjected to $12 \mathrm{kbar}$ at $25^{\circ} \mathrm{C}$ for three days. The red solution was subjected directly to column chromatography $\left(\mathrm{SiO}_{2}\right)$. Unreacted free dumbbell 3 was eluted with $\mathrm{Me}_{2} \mathrm{CO}$, whereupon the eluent was changed to $\mathrm{Me}_{2} \mathrm{CO} / \mathrm{NH}_{4} \mathrm{PF}_{6}(100: 1 \mathrm{v} / \mathrm{w})$ and a red band was collected. The eluent was then treated with cold $\mathrm{H}_{2} \mathrm{O}$. The resulting red precipitate gave a mixture of the [2] rotaxane $1 \cdot 4 \mathrm{PF}_{6}$ and a [3] rotaxane as a by-product. The red solid was redissolved in $\mathrm{Me}_{2} \mathrm{CO}$, before being subjected to column chromatography $\left(\mathrm{Al}_{2} \mathrm{O}_{3}\right)$, eluting first $\mathrm{Me}_{2} \mathrm{CO}$, continuing with $\mathrm{MeOH}$, and then with $\mathrm{MeOH} / 2 \mathrm{M} \mathrm{NH} \mathrm{NH}_{4} \mathrm{Cl}$ $(9.5: 0.5 \mathrm{v} / \mathrm{w})$ as the eluent and a red band was collected. The eluent was then treated with cold $\mathrm{H}_{2} \mathrm{O}$. The resulting red precipitate gave the desired [2]rotaxane $1.4 \mathrm{PF}_{6}(22 \mathrm{mg}, 10 \%$ yield). Selected data for [2]rotaxane 1.4 $\mathrm{PF}_{6}$ : m.p. $168-170{ }^{\circ} \mathrm{C} ;{ }^{1} \mathrm{H}$ NMR (500 $\mathrm{MHz}, \mathrm{CD}_{3} \mathrm{OD}, 25^{\circ} \mathrm{C}$, TMS): $\delta=$ $9.23(\mathrm{~d}, J=6.0 \mathrm{~Hz}, 8 \mathrm{H}), 8.08(\mathrm{~s}, 8 \mathrm{H}), 7.93(\mathrm{~d}, J=6.0 \mathrm{~Hz}, 8 \mathrm{H}), 7.86(\mathrm{~s}$,
$4 \mathrm{H}), 7.61(\mathrm{~d}, J=7.0 \mathrm{~Hz}, 2 \mathrm{H}), 7.11-7.07(\mathrm{~m}, 6 \mathrm{H}), 6.97(\mathrm{t}, J=7.0 \mathrm{~Hz}, 2 \mathrm{H})$ $6.87(\mathrm{t}, J=7.0 \mathrm{~Hz}, 2 \mathrm{H}), 6.84(\mathrm{~d}, J=7.0 \mathrm{~Hz}, 2 \mathrm{H}), 5.96(\mathrm{br}, 2 \mathrm{H}), 5.90(\mathrm{~s}$, $8 \mathrm{H}), 5.72(\mathrm{br}, 2 \mathrm{H}), 4.52(\mathrm{br}, 4 \mathrm{H}), 4.27$ (br, $4 \mathrm{H}), 4.17$ (br, 4H), 4.11 (br, $4 \mathrm{H}), 3.42(\mathrm{sep}, J=7 \mathrm{~Hz}, 2 \mathrm{H}), 1.11 \mathrm{ppm}(\mathrm{d}, J=7.0 \mathrm{~Hz}, 24 \mathrm{H})$; MS (ESI): $m / z: 1863\left[M-\mathrm{PF}_{6}\right]^{+}, 859\left[M-2 \mathrm{PF}_{6}\right]^{2+}, 524\left[M-3 \mathrm{PF}_{6}\right]^{3+}$; HRMS: calcd for $\mathrm{C}_{98} \mathrm{H}_{98} \mathrm{~F}_{12} \mathrm{~N}_{4} \mathrm{O}_{6} \mathrm{P}_{2}\left(\left[M-2 \mathrm{PF}_{6}\right]^{2+}\right)$ 858.8402, found 858.8830. Selected data for [3]rotaxane: MS (ESI): $m / z: 1409\left[M-2 \mathrm{PF}_{6}\right]^{2+}, 891\left[M-3 \mathrm{PF}_{6}\right]^{3+}$; HRMS: calcd for $\mathrm{C}_{134} \mathrm{H}_{130} \mathrm{~F}_{30} \mathrm{~N}_{8} \mathrm{O}_{6} \mathrm{P}_{5}\left(\left[M-2 \mathrm{PF}_{6}\right]^{3+}\right)$ 890.9452, found 891.1596

X-ray crystallographic analysis: CCDC-679354 contains the supplementary crystallographic data of $\mathbf{3}$ for this paper. These data can be obtained free of charge from The Cambridge Crystallographic Data Centre via www.ccdc.cam.ac.uk/data_request/cif. The crystallographic data for $2 \cdot 4 \mathrm{PF}_{6}$ and its free dumbbell-shaped compound are given in reference ${ }^{[11]}$. The data were processed by using the program SAINT ${ }^{[29]}$ to give the structure factors. The structures were solved by direct methods and refined by full-matrix least squares against $|F 2|$. Absorption corrections were based on multiple and symmetry-equivalent reflections in the data sets using the SADABS ${ }^{[30]}$ program. All non-hydrogen atoms were refined anisotropically. Hydrogen atoms were treated as idealized contributions. Scattering factors and anomalous dispersion coefficients are contained in the SHELXTL ${ }^{[31]} 6.12$ program library.

Crystal data for 3: $\mathrm{C}_{62} \mathrm{H}_{66} \mathrm{O}_{6}, M_{\mathrm{r}}=907.15$, monoclinic, space group $P 2_{1} / c$, $a=23.130(2), \quad b=11.874(1), \quad c=18.840(1) \AA, \quad \beta=98.656(1)^{\circ}, \quad V=$ $5115.3(6) \AA^{3}, \quad Z=4, \quad \rho_{\text {calcd }}=1.178 \mathrm{~g} \mathrm{~cm}^{-3}, \quad \mu\left(\mathrm{Mo}_{\mathrm{K} \alpha}\right)=0.74 \mathrm{~cm}^{-1}, \quad T=$ $100(2) \mathrm{K}$, colorless plate, $0.20 \times 0.20 \times 0.02 \mathrm{~mm}, R_{1}=0.0522[I>2 \sigma(I)]$, $w R_{2}=0.1401$ (all data), GOF $=1.017$.

\section{Acknowledgements}

This work was supported by the Microelectronics Advanced Research Corporation (MARCO) and its Focus Center Research Program (FCRP), the Center on Functional Engineered NanoArchitectonics (FENA), the Center for Nanoscale Innovation for Defense (CNID), and the National Science Foundation (NSF) (ECS-0609128).

[1] a) J. O. Jeppesen, J. Perkins, J. Becher, J. F. Stoddart, Angew. Chem 2001, 113, 1256-1261; Angew. Chem. Int. Ed. 2001, 40, 1216-1221; b) H.-R. Tseng, S. A. Vignon, J. F. Stoddart, Angew. Chem. 2003 115, 1529-1533; Angew. Chem. Int. Ed. 2003, 42, 1491-1495; c) H.R. Tseng, S. A. Vignon, P. C. Celestre, J. Perkins, J. O. Jeppesen, A Di Fabio, R. Ballardini, M. T. Gandolfi, M. Venturi, V. Balzani, J. F. Stoddart, Chem. Eur. J. 2004, 10, 155-172; d) I. Aprahamian, W. R Dichtel, T. Ikeda, J. R. Heath, J. F. Stoddart, Org. Lett. 2007, 9 , 1287-1290; e) Y.-L. Zhao, I. Aprahamian, A. Trabolsi, N. Erina, J. F. Stoddart, J. Am. Chem. Soc. 2008, 130, 6348-6350; f) Y.-L. Zhao, W. R. Dichtel, A. Trabolsi, S. Saha, I. Aprahamian, J. F. Stoddart, J. Am. Chem. Soc. 2008, 130, 11294-11296.

[2] a) P.-L. Anelli, N. Spencer, J. F. Stoddart, J. Am. Chem. Soc. 1991 113, 5131-5133; b) P.-L. Anelli, M. Asakawa, P. R. Ashton, R. A Bissell, G. Clavier, R. Gorski, A. E. Kaifer, S. J. Langford, G. Mattersteig, S. Menzer, D. Philp, A. M. Z. Slawin, N. Spencer, J. F. Stoddart, M. S. Tolley, D. J. Williams, Chem. Eur. J. 1997, 3, 1113-1135; c) J. Cao, M. C. T. Fyfe, J. F. Stoddart, G. R. L. Cousins, P. T. Glink J. Org. Chem. 2000, 65, 1937-1946; d) V. Bermudez, N. Capron, T. Gase, F. G. Gatti, F. Kajzar, D. A. Leigh, F. Zerbetto, S. Zhang, Nature 2000, 406, 608-611; e) S. J. Loeb, J. A. Wisner, Chem. Commun. 2000, 1939-1940; f) D. A. Leigh, A. Troisi, F. Zerbetto, Angew. Chem. 2000, 112, 358-361; Angew. Chem. Int. Ed. 2000, 39, 350-353; g) M. Belohradsky, A. M. Elizarov, J. F. Stoddart, Collect. Czech. Chem. Commun. 2002, 67, 1719-1728.

[3] a) D. A. Leigh, J. K. Y. Wong, F. Dehez, F. Zerbetto, Nature 2003, 424, 174-179; b) J. Berna, D. A. Leigh, M. Lubomska, S. M. Mendoza, E. M. Perez, P. Rudolf, G. Teobaldi, F. Zerbetto, Nat. Mater. 2005, 4, 704-710; c) R. A. van Delden, M. K. J. ter Wiel, M. M. Pol- 
lard, J. Vicario, N. Koumura, B. L. Feringa, Nature 2005, 437, 13371340; d) V. Balzani, M. Clemente-Leon, A. Credi, B. Ferrer, M. Venturi, A. H. Flood, J. F. Stoddart, Proc. Natl. Acad. Sci. USA 2006, 103, 1178-1183; e) B. Brough, B. H. Northrop, J. J. Schmidt, H.-R. Tseng, K. N. Houk, J. F. Stoddart, C. M. Ho, Proc. Natl. Acad. Sci. USA 2006, 103, 8583-8588; f) E. R. Kay, D. A. Leigh, F. Zerbetto, Angew. Chem. 2007, 119, 72-196; Angew. Chem. Int. Ed. 2007, 46, 72-191; g) V. Serreli, C. F. Lee, E. R. Kay, D. A. Leigh, Nature 2007, 445, 523-527; h) S. Saha, J. F. Stoddart, Chem. Soc. Rev. 2007, 36, 77-92; i) V. Balzani, A. Credi, M. Venturi, Nano Today 2007, 2, 18-25; j) S. Saha, K. C. F. Leung, T. D. Nguyen, J. F. Stoddart, J. I. Zink, Adv. Funct. Mater. 2007, 17, 685-693; k) J. Bath, A. J. Turberfield, Nat. Nanotechnol. 2007, 2, 275-284.

[4] a) C. P. Collier, G. Mattersteig, E. W. Wong, Y. Luo, K. Beverly, J. Sampaio, F. M. Raymo, J. F. Stoddart, J. R. Heath, Science 2000, 289, $1172-1175$; b) A. H. Flood, A. J. Peters, S. A. Vignon, D. W. Steuerman, H.-R. Tseng, S. Kang, J. R. Heath, J. F. Stoddart, Chem. Eur. J. 2004, 10, 6558-6564; c) E. DeIonno, H.-R. Tseng, D. D. Harvey, J. F. Stoddart, J. R. Heath, J. Phys. Chem. B 2006, 110, 7609-7612; d) J. E. Green, J. W. Choi, A. Boukai, Y. Bunimovich, E. JohnstonHalperin, E. DeIonno, Y. Luo, B. A. Sheriff, K. Xu, Y. S. Shin, H.-R. Tseng, J. F. Stoddart, J. R. Heath, Nature 2007, 445, 414-417.

[5] a) B. Odell, M. V. Reddington, A. M. Z. Slawin, N. Spencer, J. F. Stoddart, D. J. Williams, Angew. Chem. 1988, 100, 1605-1608; Angew. Chem. Int. Ed. Engl. 1988, 27, 1547-1550; b) M. Asakawa, W. Dehaen, G. L'abbé, S. Menzer, J. Nouwen, F. M. Raymo, J. F. Stoddart, D. J. Williams, J. Org. Chem. 1996, 61, 9591-9595; c) G. Doddi, G. Ercolani, P. Mencarelli, A. Piermattei, J. Org. Chem. 2005, 70, 3761-3764.

[6] a) J. O. Jeppesen, K. A. Nielsen, J. Perkins, S. A. Vignon, A. Di Fabio, R. Ballardini, M. T. Gandolfi, M. Venturi, V. Balzani, J. Becher, J. F. Stoddart, Chem. Eur. J. 2003, 9, 2982-3007; b) J. O. Jeppesen, S. Nygaard, S. A. Vignon, J. F. Stoddart, Eur. J. Org. Chem. 2005, 196220.

[7] a) B. W. Laursen, S. Nygaard, J. O. Jeppesen, J. F. Stoddart, Org. Lett. 2004, 6, 4167-4170; b) J. W. Choi, A. H. Flood, D. W. Steuerman, S. Nygaard, A. B. Braunschweig, N. N. P. Moonen, B. W. Laursen, Y. Luo, E. DeIonno, A. J. Peters, J. O. Jeppesen, K. Xu, J. F. Stoddart, J. R. Heath, Chem. Eur. J. 2006, 12, 261-279.

[8] a) T. J. Huang, B. Brough, C. M. Ho, Y. Liu, A. H. Flood, P. A. Bonvallet, H.-R. Tseng, J. F. Stoddart, M. Baller, S. Magonov, Appl. Phys. Lett. 2004, 85, 5391-5393; b) Y. Liu, A. H. Flood, P. A. Bonvallett, S. A. Vignon, B. H. Northrop, H.-R. Tseng, J. O. Jeppesen, T. J. Huang, B. Brough, M. Baller, S. Magonov, S. D. Solares, W. A. Goddard, C. M. Ho, J. F. Stoddart, J. Am. Chem. Soc. 2005, 127, 9745-9759.

[9] J. O. Jeppesen, S. A. Vignon, J. F. Stoddart, Chem. Eur. J. 2003, 9, 4611-4625.

[10] S. Nygaard, K. C. F. Leung, I. Aprahamian, T. Ikeda, S. Saha, B. W. Laursen, S. Y. Kim, S. W. Hansen, P. C. Stein, A. H. Flood, J. F. Stoddart, J. O. Jeppesen, J. Am. Chem. Soc. 2007, 129, 960-970.

[11] I. Yoon, O. Š. Miljanić, D. Benítez, S. I. Khan, J. F. Stoddart, Chem. Commun. 2008, 4561-4563.

[12] a) D. H. Busch, N. A. Stephenson, Coord. Chem. Rev. 1990, 100, 119-154; b) S. Anderson, H. L. Anderson, J. K. M. Sanders, Acc. Chem. Res. 1993, 26, 469-475; c) G. A. Breault, C. A. Hunter, P. C. Mayers, Tetrahedron 1999, 55, 5265-5293; d) Templated Organic Synthesis (Eds.: F. Diederich, P. J. Stang), Wiley-VCH, Weinheim, 2000; e) M. J. Blanco, J. C. Chambron, M. C. Jimenez, J. P. Sauvage, Top. Stereochem. 2003, 23, 125-173; f) D. H. Busch, Top. Curr. Chem. 2005, 249, 1-65; g) C. D. Meyer, C. S. Joiner, S. J. Cantrill, J. F. Stoddart, Chem. Soc. Rev. 2007, 36, 1705-1723; h) K. E. Griffiths, J. F. Stoddart, Pure Appl. Chem. 2008, 80, 485-506.

[13] F.-G. Klärner, F. Wurche, J. Prakt. Chem. 2000, 7, 609-636.

[14] S. L. Mayo, B. D. Olafson, W. A. Goddard, J. Phys. Chem. 1990, 94, $8897-8909$. The total potential energy is given by the sum of the van der Waals, electrostatic, bond stretching, angle bending, torsion, and inversion energy components. The particle-particle, particlemesh Ewald (PPPM) method was used for the long-range electrostatic interaction correction

[15] a) K. Sonogashira, Y. Tohda, N. Hagihara, Tetrahedron Lett. 1975, 50, 4467-4470; b) S. Takahashi, Y. Kuroyama, K. Sonogashira, N. Hagihara, Synthesis 1980, 627-630.

[16] P.-L. Anelli, P. R. Ashton, R. Ballardini, V. Balzani, M. Delgado, M. T. Gandolfi, T. T. Goodnow, A. E. Kaifer, D. Philp, M. Pietraszkiewicz, L. Prodi, M. V. Reddington, A. M. Z. Slawin, N. Spencer, J. F. Stoddart, C. Vicent, D. J. Williams, J. Am. Chem. Soc. 1992, 114, 193-218.

[17] a) O. Š. Miljanić, W. R. Dichtel, S. Mortezaei, J. F. Stoddart, Org. Lett. 2006, 8, 4835-4838; b) O. Š. Miljanić, W. R. Dichtel, S. I. Khan S. Mortezaei, J. R. Heath, J. F. Stoddart, J. Am. Chem. Soc. 2007 129, 8236-8246

[18] a) G. Eglinton, A. R. Galbraith, Chem. Ind. 1956, 737-738; b) P. Siemsen, R. C. Livingston, F. Diederich, Angew. Chem. 2000, 112, 2740-2767; Angew. Chem. Int. Ed. 2000, 39, 2632-2657.

[19] For accounts and reviews on $[\mathrm{C}-\mathrm{H} \cdots \pi]$ interactions, see: a) M. Nishio, Y. Umezawa, M. Hirota, Y. Takeuchi, Tetrahedron 1995, 51, 8665-8701; b) Y. Umezawa, S. Tsuboyama, K. Honda, J. Uzawa, M. Nishio, Bull. Chem. Soc. Jpn. 1998, 71, 1207-1213; c) M. Nishio, M Hirota, Y. Umezawa, The $[C-H \cdots \pi]$ Interaction. Evidence, Nature and Consequences, Wiley, New York, 1998.

[20] S. Kang, S. A. Vignon, H.-R. Tseng, J. F. Stoddart, Chem. Eur. J. 2004, 10, 2555-2563.

[21] The free energy of activation, $\Delta G_{\mathrm{c}}{ }^{*}$ was calculated by the Eyring equation, $\Delta G_{\mathrm{c}}^{\neq}=-R T_{\mathrm{c}} \ln \left(k_{\mathrm{ex}} h / k_{\mathrm{b}} T_{\mathrm{c}}\right), k_{\mathrm{ex}}=(\pi \Delta v) / \sqrt{ } 2$. See: a) F. P. Gasparro, N. H. Kolodny, J. Chem. Educ. 1977, 54, 258-261; b) Dynamic NMR Spectroscopy (J. Sandstrom), Academic Press, New York, 1982; c) M. Ōki, Applications of Dynamic NMR Spectroscopy to Organic Chemistry, VCH, Weinheim, 1985.

[22] F. M. Raymo, M. D. Bartberger, K. N. Houk, J. F. Stoddart, J. Am. Chem. Soc. 2001, 123, 9264-9267.

[23] For accounts and reviews on $\pi-\pi$ stacking interactions, see: a) C. A Hunter, J. K. M. Sanders, J. Am. Chem. Soc. 1990, 112, 5525-5534; b) F. Cozzi, J. S. Siegel, Pure Appl. Chem. 1995, 67, 683-689; c) A. S. Shetty, J. S. Zhang, J. S. Moore, J. Am. Chem. Soc. 1996, 118, 1019-1027.

[24] a) Y. H. Jang, S. S. Jang, W. A. Goddard, J. Am. Chem. Soc. 2005 , 127, 4959-4964; b) S. S. Jang, Y. H. Jang, Y. H. Kim, W. A. Goddard, J. W. Choi, J. R. Heath, B. W. Laursen, A. H. Flood, J. F. Stoddart, K. Norgaard, T. Bjornholm, J. Am. Chem. Soc. 2005, 127, 1480414816 ; c) S. S. Jang, Y. H. Jang, Y. H. Kim, W. A. Goddard, A. H. Flood, B. W. Laursen, H.-R. Tseng, J. F. Stoddart, J. O. Jeppesen, J. W. Choi, D. W. Steuerman, E. Delonno, J. R. Heath, J. Am. Chem Soc. 2005, 127, 1563-1575; d) Y. H. Kim, S. S. Jang, W. A. Goddard, Appl. Phys. Lett. 2006, 88,163112 .

[25] A. K. Rappe, W. A. Goddard, J. Phys. Chem. 1991, 95, 3358-3363.

[26] B. D. Olafson, W. A. Goddard, Lingraf release 3.23, Materials and Process Simulation Center, Caltech. 2007.

[27] A. v. D. Vaart, Theor. Chem. Acc. 2006, 116, 183-193.

[28] The simulations were performed using the canonical ensemble (TVN) MD, using the Nose-Hoover thermostat with a relaxation time of $0.1 \mathrm{ps}$. The equation of motion was integrated by the Verlet algorithm with a time step of $1.0 \mathrm{fs}$.

[29] SAINTPLUS Version 6.22, Brüker AXS, Madison, 2001

[30] G. M. Sheldrick, SADABS: Program for Scaling and Correction of Area Detector Data, University of Göttingen, 1998.

[31] G. M. Sheldrick, SHELXTL Version 6.12, Brüker AXS, Madison, 2000.

Received: October 9, 2008 Published online: December 22, 2008 